\title{
Article \\ The Antimicrobial Activity of Omiganan Alone and in Combination against Candida Isolated from Vulvovaginal Candidiasis and Bloodstream Infections
}

\author{
Dawid Żyrek ${ }^{1}$, Andrzej Wajda ${ }^{1}$, Paulina Czechowicz ${ }^{1, *} \mathbb{B}$, Joanna Nowicka ${ }^{1, *}$, Maciej Jaśkiewicz ${ }^{2}$ (D), \\ Damian Neubauer ${ }^{2}$ (D) and Wojciech Kamysz ${ }^{2}$ \\ 1 Department of Microbiology, Faculty of Medicine, Wrocław Medical University, 50-367 Wrocław, Poland; \\ dawid.zyrek96@gmail.com (D.Ż.); andrzej.wajda96@gmail.com (A.W.) \\ 2 Department of Inorganic Chemistry, Faculty of Pharmacy, Medical University of Gdańsk, \\ 80-416 Gdańsk, Poland; mj@gumed.edu.pl (M.J.); damian.neubauer@gumed.edu.pl (D.N.); \\ wojciech.kamysz@gumed.edu.pl (W.K.) \\ * Correspondence: paulina.czechowicz.umedwroc@gmail.com (P.C.); joanna.nowicka@umed.wroc.pl (J.N.)
}

\section{check for} updates

Citation: Żyrek, D.; Wajda, A.; Czechowicz, P.; Nowicka, J.;

Jaśkiewicz, M.; Neubauer, D.; Kamysz, W. The Antimicrobial Activity of Omiganan Alone and in Combination against Candida Isolated from Vulvovaginal Candidiasis and Bloodstream Infections. Antibiotics 2021, 10, 1001. https://doi.org/ 10.3390/antibiotics10081001

Academic Editor: Samir Jawhara

Received: 26 July 2021

Accepted: 17 August 2021

Published: 19 August 2021

Publisher's Note: MDPI stays neutral with regard to jurisdictional claims in published maps and institutional affiliations.

Copyright: (c) 2021 by the authors. Licensee MDPI, Basel, Switzerland. This article is an open access article distributed under the terms and conditions of the Creative Commons Attribution (CC BY) license (https:/ / creativecommons.org/licenses/by/ $4.0 /)$.

\begin{abstract}
Fungi from the Candida genus are widespread commensals and, at the same time, are the leading cause of fungal infections worldwide. For instance, vulvovaginal candidiasis (VVC) affects approximately $75 \%$ of women at least once in their lifetime, remaining the second most common gynecological infection. On the contrary, hospital-acquired fungal bloodstream infections (BSIs), although less frequent, are characterized by a high mortality rate. Undoubtedly, the main reason for this situation are virulence factors that these yeast-like fungi can produce, and the ability to form a biofilm is one of the most important of them. Due to the low effectiveness of classic antimycotics against Candida biofilms, an intense search for new drugs capable of eradicating this structure is highly demanded. One of the most promising groups of compounds exhibiting such properties are antimicrobial peptides (AMPs). This study focuses on a comparison of the efficacy of Omiganan and fluconazole alone and in combination against Candida strains isolated from BSIs. The obtained results are consistent with our previous reports on the effectiveness of Omiganan against clinical strains isolated from VVC. This is also the first report on the combinatory application of Omiganan in the context of fungal BSI. The majority of combinations with fluconazole showed an additive effect, as well as a synergistic effect in the range of certain concentrations. Importantly, such effects are visible at concentrations much lower than for those compounds used individually. Potentially, this entails the possibility of limiting the adverse effects (e.g., toxicity) of Omiganan and fluconazole applied in vivo, thus improving the safety profile of this particular antifungal therapy.
\end{abstract}

Keywords: Candida; biofilm; antimicrobial peptides; fluconazole; Omiganan

\section{Introduction}

Candida species are widespread commensals that can be part of the microbiota of mucous membranes and skin. Moreover, some data show that they even occur in 50-70\% of the population [1,2]. Despite the fact that Candida spp. belong to normal flora, they may lead to opportunistic infections and, at the same time, they are indicated as a frequent cause of symptomatic infections all over the world [3].

Vulvovaginal candidiasis (VVC) is diagnosed if the typical symptoms of vaginitis and vulvitis are accompanied by the presence of Candida spp. in a material obtained from the external genitalia [4]. VVC affects approximately 75\% of women at least once during their lifetime, which makes it the second most common vulvovaginal infection in the world, after bacterial vaginosis (BV) [5]. In more than half of cases, VVC occurs at least twice a lifetime, and in 5-8\%, at least four times a year (recurrent vulvovaginal candidiasis (RVVC)) [6]. For instance, recent epidemiological data indicate that RVVC affects nearly 
138 million women annually (500 million women during their lifetime), and the number of these infections is constantly increasing. [7,8].

In fact, Candida spp. are noticed in every fifth healthy woman's vaginal swabs, and the most common risk factors are pregnancy, hormone replacement therapy, diabetes, states of compromised immunity, antibiotic therapy, and steroid therapy $[6,9,10]$. In the majority of cases (80-95\%), the etiological factor of VVC is Candida albicans; however, recently, the percentage of infections caused by other species belonging to this genus (non-Candida albicans Candida (NCAC)), such as C. glabrata, C. parapsilosis, C. krusei, and C. tropicalis, is increasing. In some populations, they are responsible for every fifth fungal vaginosis, occurring even more often in RVVC [6,10-13]. NCAC are usually characterized by a higher virulence and a weaker response to standard antifungal treatment, which often results in therapeutic failures [14]. Although vaginal candidiasis does not increase overall mortality, it significantly worsens the quality of life of a large number of women, causing pain, burning sensations, and discomfort, both physical and psychological, resulting in poorer self-esteem and decreased sexual satisfaction [6].

This means that VVC has become a serious and global threat, especially when considering the growing number of incidences, as well as the costs for the healthcare system. Undoubtedly, the main reason for this situation is the decreased susceptibility or resistance of Candida strains to azoles [15]. It should be noted that low effectiveness of the commonly used antifungals leads to prolonged therapy, which secondarily induces resistance. For C. albicans, several mechanisms have been described. For example, the most common are mutations in the ERG11 gene and overexpression of the efflux pumps associated genes (e.g., CDR and MDR1). The first leads to the lowered affinity of drugs, while the second prevents intracellular accumulation [16,17]. Other mechanisms include over-expression of membrane transporters and mutations in genes associated with the biosynthesis and import of sterols [18].

In bloodstream infections (BSIs), fungal cells infiltrate the systemic circulation in large numbers. As a result, they can invade internal organs and tissues, and can cause symptoms of sepsis. The most important risk factor for BSI is immunodeficiency, especially neutropenia, but other ones, such as cancer, diabetes, postoperative conditions, and treatment in the intensive care unit, cannot be ignored. Nowadays, the frequency of invasive fungal infections is increasing [19]. In fact, C. albicans is an etiological factor in approximately half of all cases $[20,21]$. However, recent data highlight that the number of infections caused by NCAC such as C. dubliniensis, C. glabrata, C. guilliermondii, C. kefyr, C. krusei, C. parapsilosis, and C. tropicalis is still rising [2,22]. Nevertheless, the multitude of virulence factors of Candida spp., increasing the resistance to standard antifungal drugs and the fact that BSIs mainly affect patients with comorbidities, often in profound immunosuppression, determine the poor prognosis of this group of patients [2,23,24].

Among the virulence factors of some yeast-like fungi, the ability to create a biofilm is one of the most important for their pathogenicity. It seems to be essential primarily in the case of chronic and recurrent mucocutaneous candidiasis, including RVVC, and infections related to biomaterials (artificial valves, endoprostheses, and intravascular or urinary catheters). Biofilms are characterized by a high resistance to antifungal drugs, even at very high concentrations $[25,26]$.

Due to the low effectiveness of classic antifungals against Candida biofilms, an intense search for new drugs effective against this structure has arisen recently. Recent advances in this field include a quaternary ammonium derivative of pyridoxine and terbinafine with antibiofilm activity against both Candida and bacterial strains [27]. Studies are focused not only on derivatization, but also on the potentiation of antifungal activity of terbinafine and azoles by, e.g., the synergistic effect of 2(5H)-furanone derivative [28]. A relatively new and very promising group of compounds exhibiting such properties are antimicrobial peptides (AMPs), characterized by a unique mechanism of action and a relatively low potential for generating resistance $[29,30]$. 
Omiganan is a synthetic analog of indolicidin-a peptide primarily isolated from granules of bovine neutrophils [31]. Moreover, this molecule has been subjected to the final phase of clinical trials in the treatment of rosacea, juvenile acne, atopic dermatitis, genital warts, and vulvar intraepithelial neoplasia (VIN) [32-35]. The initial results also showed great potential in the treatment of fungal infections [36,37]. This study focuses on a comparison of the efficacy of Omiganan and fluconazole and their combination against planktonic forms and biofilms of blood-derived and vaginal isolates of Candida spp.

\section{Materials and Methods}

\subsection{Microorganisms}

The studies were conducted on clinical strains of various Candida species, including 32 isolates acquired from women with VVC and 30 isolates from patients with candidemia (BSI). Among the VVC strains, 30 were identified as C. albicans, and the other two were C. lusitaniae and C. kefyr. NCAC strains accounted for the majority (21/30) of the blood-derived isolates. These included 10 strains of $C$. glabrata, four strains of $C$. parapsilosis, three strains of C. krusei, two strains of $C$. tropicalis, and two strains of $C$. kefyr. The remaining nine isolates were C. albicans strains. All clinical strains were obtained from the internal collection of the Department of Microbiology, Wroclaw Medical University. Two reference strains (C. albicans ATCC 90028 and C. glabrata ATCC 15126) were obtained from the Polish Collection of Microorganisms (Polish Academy of Sciences, Wroclaw, Poland).

\subsection{Peptide Synthesis}

Omiganan (ILRWPWWPWRRK-NH ${ }_{2}$ ) was synthesized as described previously [38]. The peptide was synthesized manually by the solid-phase method using Fmoc chemistry on polystyrene Rink amide resin with a loading of $1.0 \mathrm{mmol} / \mathrm{g}$ (Orpegen Peptide Chemicals GmbH, Heidelberg, Germany). Single deprotection of the Fmoc group was performed with a $20 \%(v / v)$ piperidine (Merck, Darmstadt, Germany) solution in DMF (Honeywell, Seelze, Germany) for $15 \mathrm{~min}$. Acylation of Fmoc-AA-OH was conducted in a $\operatorname{DCM} / \operatorname{DMF}(1: 1, v / v)$ solution with OxymaPure and DIC as coupling reagents (equimolar mixture of reagents) for $1.5 \mathrm{~h}$ using a threefold molar excess based on the resin. Every step was preceded by rinsing the resin and running the chloranil test. Cleavage of Omiganan was accomplished in TFA (Apollo Scientific, Denton, UK) and scavengers' mixture-TIS (Sigma-Aldrich, St. Louis, MO, USA), phenol (Sigma-Aldrich, St. Louis, MO, USA), and deionized water (92.5:2.5:2.5:2.5, $v / v / v / v)$ for $1.5 \mathrm{~h}$ with agitation. The cleaved peptide was precipitated with cold diethyl ether and lyophilized. Omiganan was purified by reversed-phase high-performance liquid chromatography, and its identity was confirmed by mass spectrometry (ESI-MS).

\subsection{Antimicrobial Activity}

In the first stage of the study, the minimum inhibitory concentrations (MICs) for each strain were determined. The MIC values were evaluated by the microdilution method using RPMI 1640 in accordance to the CLSI recommendations [39]. Suspensions of the tested strains $\left(0.5-2.5 \times 10^{3} \mathrm{CFU} / \mathrm{mL}\right)$ were applied to 96-well polystyrene plates with previously prepared serial dilutions of fluconazole or Omiganan ranging in concentration from 0.125 to $256 \mu \mathrm{g} / \mathrm{mL}$. The plates were incubated for $24 \mathrm{~h}$ at $37^{\circ} \mathrm{C}$, and subsequently, the MICs were read. In the case of the fungistatic azole, the optical density (OD) was read spectrophotometrically (BiochromAsys UVM 340) at a wavelength of $530 \mathrm{~nm}$. The MIC was considered as the concentration at which the growth inhibition of at least $50 \%$ of microorganisms was detected. For this purpose, the following equation was used: $\left.\left(\mathrm{OD}_{\text {well }}-\mathrm{OD}_{\mathrm{K}_{-}}\right) /\left(\mathrm{OD}_{\mathrm{K}+}-\mathrm{OD}_{\mathrm{K}_{-}}\right) \times 100 \%\right)$, where $\mathrm{OD}_{\text {well }}$ is the absorbance of the wellbeing assessed, $\mathrm{OD}_{\mathrm{K}-}$ is the value for the negative control (background), and $\mathrm{OD}_{\mathrm{K}+}$ is the value obtained in the control positive (strain growth control). With regard to the peptide, the visual method was adapted, considering the minimum inhibitory concentration value at which no turbidity, indicative of fungal growth, was observed. All experiments 
were conducted in triplicate and included a strain growth control (positive control) and a negative control, which served as a medium sterility test.

In the next stage, the minimum biofilm eradication concentrations (MBECs) were determined. Prepared microbial suspensions with a density of $1-5 \times 10^{6} \mathrm{CFU} / \mathrm{mL}$ in RPMI 1640 medium were transferred to 96-well plates and incubated for $24 \mathrm{~h}$ at $37^{\circ} \mathrm{C}$. The pre-formed biofilm was then washed three times with a sterile $0.9 \% \mathrm{NaCl}$ solution. Then, the test compounds were added to ranging concentrations of Omiganan $(0.125-256 \mu \mathrm{g} / \mathrm{mL})$ and fluconazole $(0.25-512 \mu \mathrm{g} / \mathrm{mL})$. After $24 \mathrm{~h}$ of incubation at $37^{\circ} \mathrm{C}$, a solution of MTT (3-(4,5-Dimethylthiazol-2-yl)-2,5-Diphenyltetrazolium Bromide) at a concentration of $1 \mathrm{mg} / \mathrm{mL}$ was added to each well and incubated for $3 \mathrm{~h}$ at $37^{\circ} \mathrm{C}$ in the dark. Then, the results were read visually. The concentration at which no color change was observed (yellow MTT is reduced by living cells to dark colored formazan) was considered as the MBEC [40]. All experiments were conducted in triplicate and included positive and negative controls.

A preliminary assessment of the interaction between both compounds was carried out by determining the fractional inhibitory concentration index (FIC index) using the checkerboard method [41]. This assay was conducted on 24 randomly selected strains, including C. albicans ATCC 90028 and C. glabrata ATCC 15126, 10 VVC-derived strains, and 12 BSI-derived strains. The strains were numbered, and a randomization program (http:/ / www.graphpad.com/quickcalcs/index.cfm, accessed date: 15 June 2021) was used for selection. To determine the FIC index value, 96-well plates containing serial dilutions of fluconazole (horizontal) and Omiganan (vertical) were prepared. Such an approach provided a final concentration range of $0.5-64 \mu \mathrm{g} / \mathrm{mL}$ for both compounds. Then, strain suspensions prepared analogically to those during the MIC determination were added to the wells of the plate. After $24 \mathrm{~h}$ of incubation at $37^{\circ} \mathrm{C}$, the plates were read visually, and the inhibitory concentrations were taken as those for which no growth of microorganisms was observed. The experiments were conducted in triplicate and included a positive control and a negative control. The following formulas were used to determine the FIC index:

$$
\begin{gathered}
\frac{\mathrm{A}}{\mathrm{MIC}_{\mathrm{A}}}+\frac{\mathrm{B}}{\mathrm{MIC}_{\mathrm{B}}}=\mathrm{FIC}_{\mathrm{A}}+\mathrm{FIC}_{\mathrm{B}}=\mathrm{FIC}, \\
\text { FIC index }=\frac{\sum \mathrm{FIC}}{\mathrm{n}}
\end{gathered}
$$

Compound A was fluconazole and compound B was Omiganan. The MIC concentrations previously determined for each strain were taken into account during the calculations. The values of $\mathrm{A}$ and $\mathrm{B}$ were the concentrations determined using the checkerboard method $(n=8)$. The described method is presented in Supplementary Table S1.

The FIC index values, obtained as described above, were interpreted in accordance with the recommendations [41], which are presented in Table 1.

Table 1. Interpretation of the interactions between the two compounds tested using the checkerboard method, based on of the obtained FIC index values.

\begin{tabular}{cc}
\hline FIC Index & Interpretation \\
\hline$\leq 0.5$ & Synergism (SYN) \\
$>0.5$ to 1.0 & Addition (ADD) \\
$>1.0$ to $\leq 2.0$ & Indifference (IND) \\
$>2.0$ & Antagonism (ANT) \\
\hline
\end{tabular}

\section{Results}

\subsection{Minimum Inhibitory Concentration (MIC)}

In the case of the VVC-derived isolates, all strains were found to be sensitive to fluconazole, and the highest MIC value was $1 \mu \mathrm{g} / \mathrm{mL}$ (C. kefyr). For the vast majority of strains $(27 / 32,85 \%)$ the obtained MIC was $0.125 \mu \mathrm{g} / \mathrm{mL}$ or less. Among the BSI-derived strains, the distribution of the MIC values was less heterogeneous and ranged from $\leq 0.125$ 
to $64 \mu \mathrm{g} / \mathrm{mL}$. The most common MIC was $0.125 \mu \mathrm{g} / \mathrm{mL}$ or less $(7 / 30,23 \%)$. The value of the minimum inhibitory concentration for fluconazole was not species-dependent. The MIC value distribution of fluconazole is presented in Figure 1.

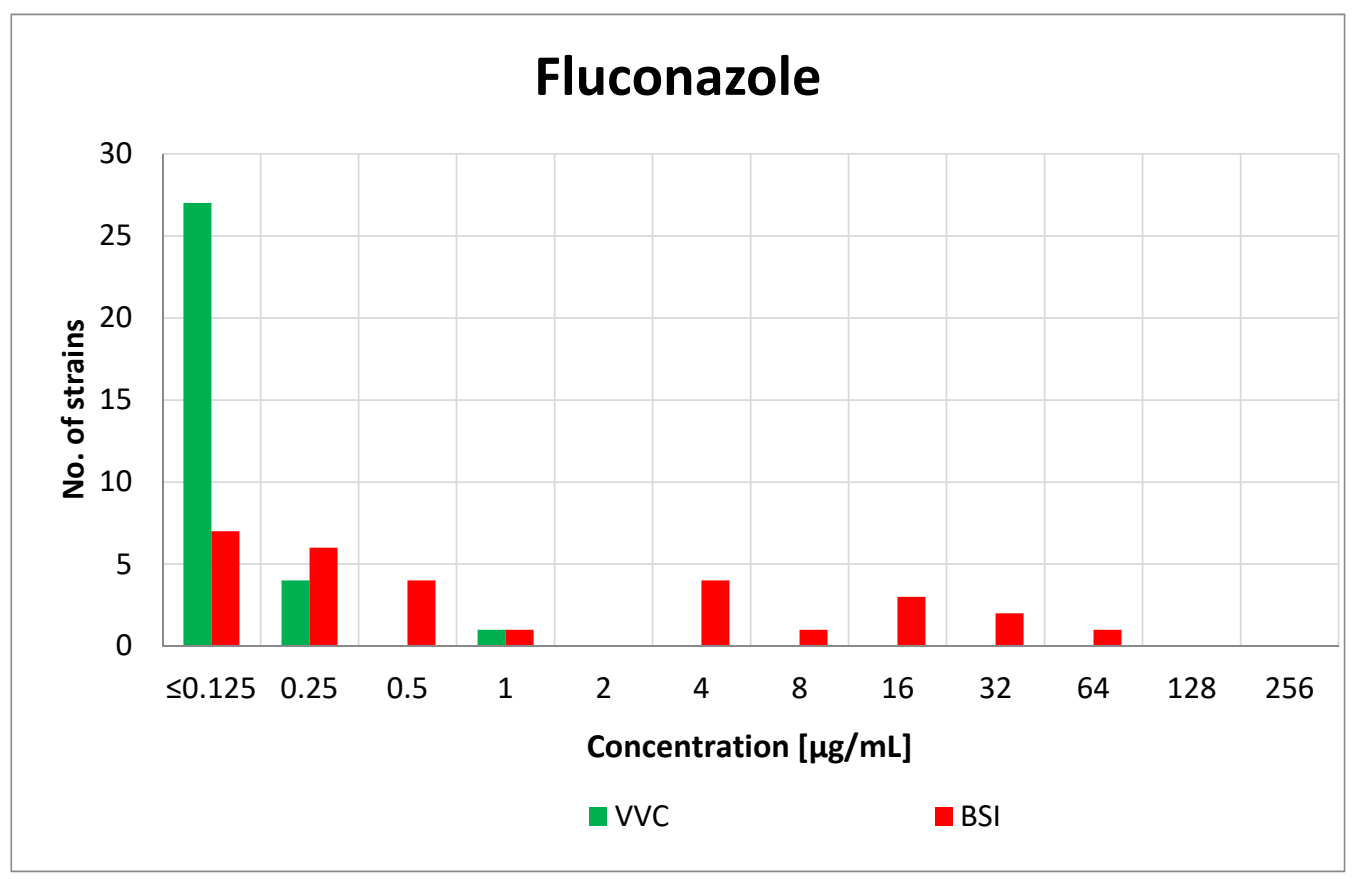

Figure 1. Distribution of the MICs of fluconazole among the vaginal (VVC) and blood-derived (BSI) Candida strains.

Omiganan turned out to be active against the tested fungi in the concentration range of 32-256 $\mu \mathrm{g} / \mathrm{mL}$. For the vaginal strains, the most common MIC value was $128 \mu \mathrm{g} / \mathrm{mL}$ $(19 / 32,59 \%)$. Both of the VVC-derived NCAC species presented lower MICs $(64 \mu \mathrm{g} / \mathrm{mL})$ than the other vaginal C. albicans strains. The MIC value among the blood-derived isolates was not dependent on the species, and the dominant MIC was $256 \mu \mathrm{g} / \mathrm{mL}(17 / 30,57 \%)$. The MIC results for Omiganan are presented in Figure 2. Detailed data on the obtained MIC values of fluconazole and Omiganan are available in Supplementary Material in Tables S2-S4.

To determine the selectivity of Omiganan toward human and Candida cells, we referred to previous results from cytotoxicity studies $\left(\mathrm{IC}_{50}\right)$ against $\mathrm{HaCaT}$ cell line (immortalized human keratinocytes) conducted by Jaśkiewicz et al. [42]. The $\mathrm{IC}_{50}$ value was included in the Selectivity Index (SI) calculation, which is its quotient and the geometric mean (GM) of the obtained MIC in this research. The results are shown in Table 2.

Table 2. Geometric mean of the MIC values (GM), $\mathrm{IC}_{50}$, and calculated Selectivity Index (SI) of Omiganan against combined vaginal (VVC) and blood-derived (BSI) Candida strains.

\begin{tabular}{cccc}
\hline Peptide & GM & IC $_{50}$ [42] & SI \\
\hline Omiganan & 166.43 & 79.39 & 0.48 \\
\hline
\end{tabular}




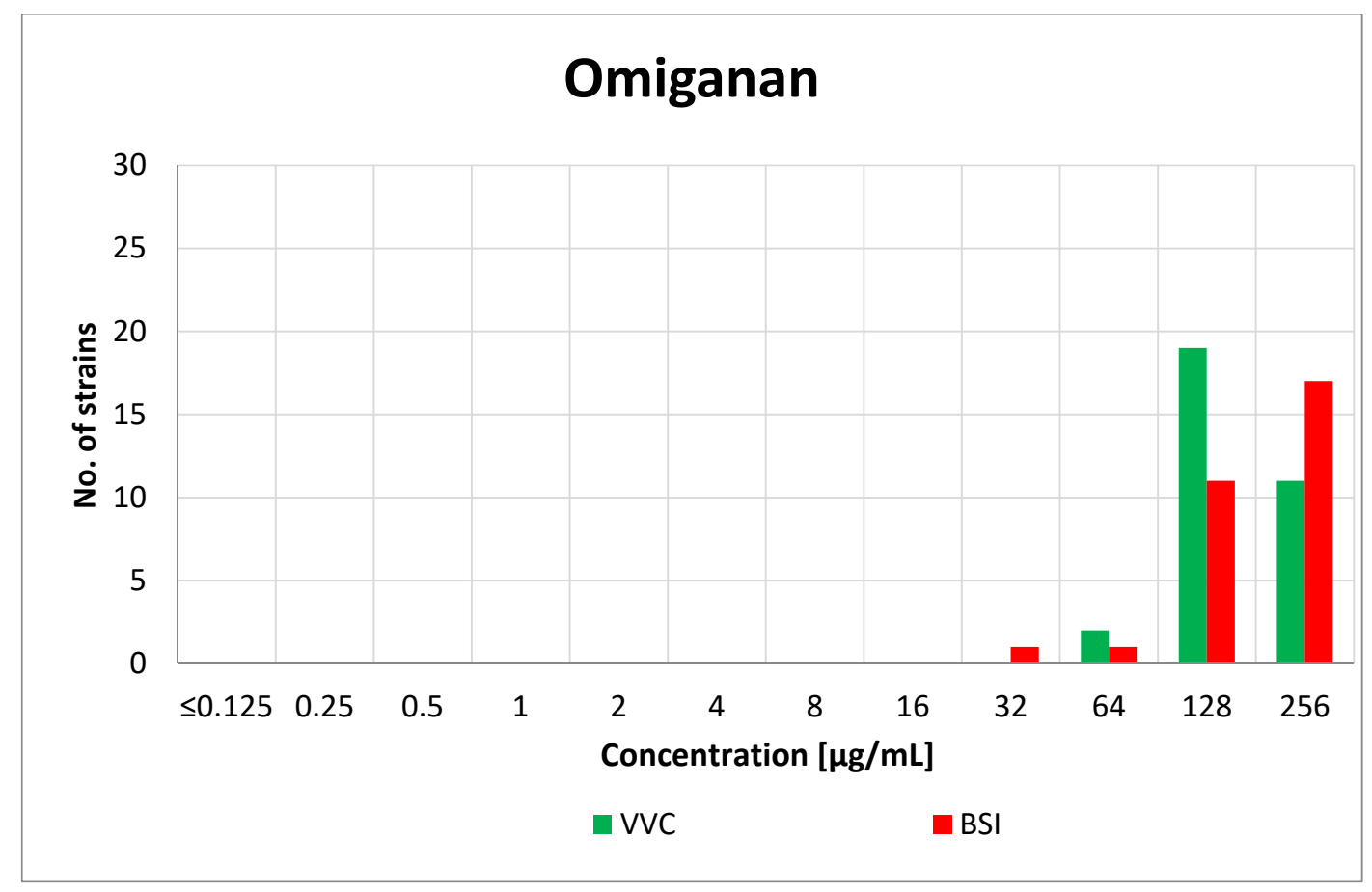

Figure 2. Distribution of the MICs of Omiganan among the vaginal (VVC) and blood-derived (BSI) Candida strains.

\subsection{Minimal Biofilm Eradication Concentration (MBEC)}

Fluconazole was ineffective in eradicating the biofilms of both the VVC and BSI-derived isolates. In both strain pools, the dominant MBEC value was $512 \mu \mathrm{g} / \mathrm{mL}(17 / 32,53 \%$ for vaginal strains; $17 / 30,57 \%$ for blood-derived strains). For the remaining isolates, the MBEC exceeded the applied concentration range. There were no noticeable differences in the distribution of MBECs between the VVC and BSI Candida isolates.

In the case of Omiganan, the MBEC values against almost all of the tested strains were equal to $256 \mu \mathrm{g} / \mathrm{mL}$. Among the VVC strains, this value was observed in $97 \%$ of cases $(31 / 32)$. Only one of the $C$. albicans isolates was characterized by a lower MBEC value $(128 \mu \mathrm{g} / \mathrm{mL})$. For all blood isolates, these values were equal to $256 \mu \mathrm{g} / \mathrm{mL}$. Detailed data on the obtained MBEC values of fluconazole and Omiganan are available in Supplementary Material in Tables S2-S4.

\subsection{FIC Index}

The study of the interaction between fluconazole and Omiganan clearly showed an overall additive effect of the combination of these two compounds. The FIC index value for 21 out of the 24 tested strains did not exceed 1, which, according to the commonly accepted interpretation, indicates addition. For the remaining three isolates (identified as C. albicans) this effect was indifferent. In both the vaginal and blood-derived strains, the addition was the most common effect and affected the majority of $C$. albicans isolates $(6 / 8$ with VVC and $5 / 6$ with BSI) and $100 \%$ of the strains from the NCAC group. The described results are shown in Figure 3.

As the obtained FIC indexes are the arithmetic means of eight individual FIC values calculated for various concentrations of the tested compounds, the search for the most favorable specific combination of fluconazole and Omiganan concentrations was based on the analysis of individual FICs. For each individual strain, there was a specific combination of the concentrations of fluconazole-Omiganan at which growth inhibition was observed. Taking into account such combinations and their interpretation, for 12 (out of 24) strains, it was possible to determine at least one FIC value $\left(\mathrm{FIC}_{\mathrm{A}}+\mathrm{FIC}_{\mathrm{B}}\right)$, indicating a synergistic effect (FIC $\leq 0.5$ ). Similarly, for two out of the three strains for which an indifferent effect of the combination of fluconazole and Omiganan was observed (FIC index), it was 
possible to achieve an additive effect at specific compound concentrations. The peptide concentrations in the synergistic and additive combinations with fluconazole were at least one-half lower than the corresponding MICs of Omiganan alone. A comparison of the MIC values of Omiganan with the peptide concentrations indicative of the most favorable effect in combination with fluconazole for the 24 isolates tested in the checkerboard method are shown in Figure 4. The geometric mean of the MICs obtained for Omiganan was 147.89, while in case of combination of compounds, the GM of this peptide was 49.35. Detailed data on the obtained FIC values are available in Supplementary Material in Table S5.

A

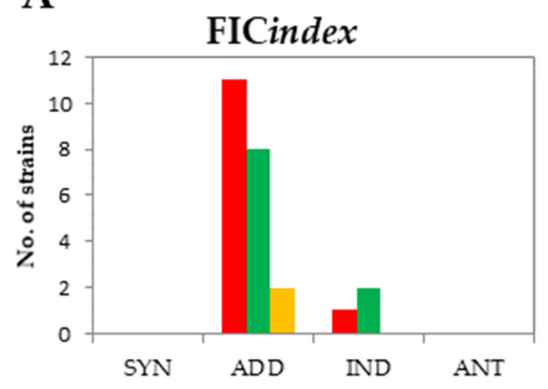

B

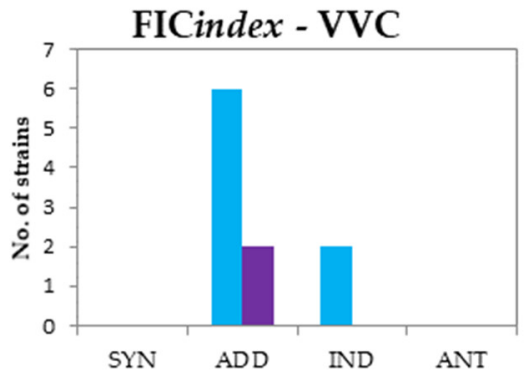

C. albicans $\quad$ NCAC
C

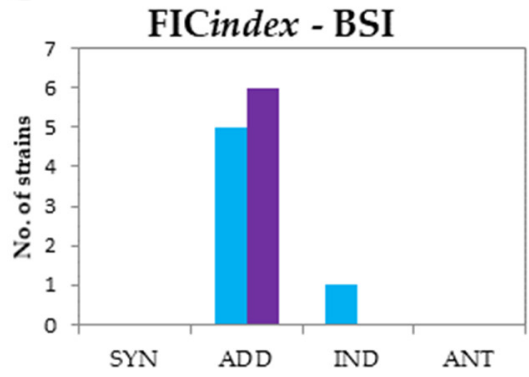

C.albicans

$\square$ NCAC

Figure 3. Cumulative FIC index results (checkerboard method) with the interpretation of the obtained effects of the fluconazole-Omiganan interaction. (A) Interpretation of the determined FIC indices with differentiation between vaginal (VVC) strains, blood-derived (BSI) isolates, and reference strains (marked as "ref."). (B) Interpretation of the determined FIC indices against vaginal strains (VVC). (C) Interpretation of the determined FIC indices against the blood-derived strains (BSI).

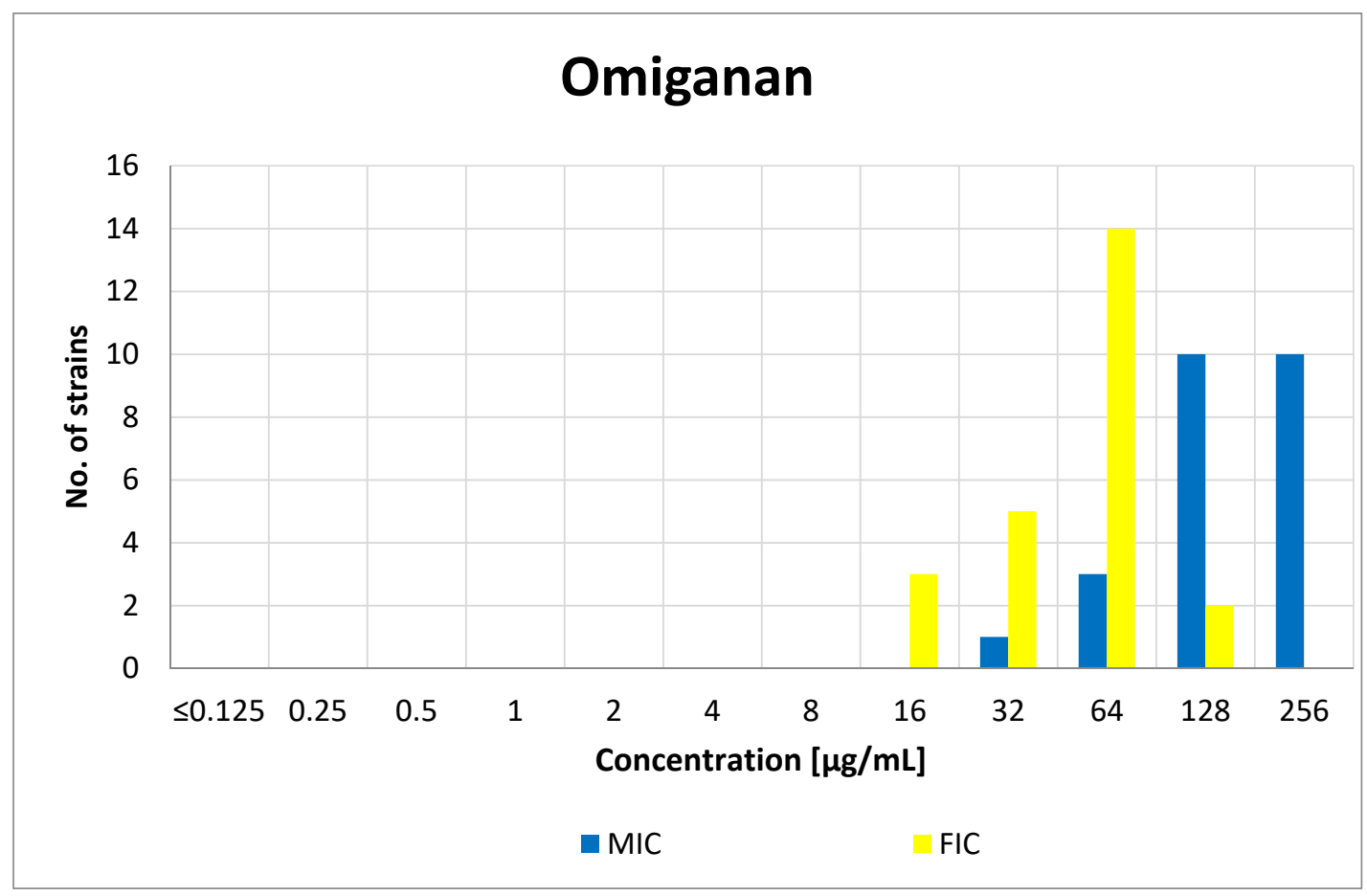

Figure 4. Distribution of the minimum inhibitory concentrations (MICs) of Omiganan and its concentrations at the lowest FIC that indicate synergy or addition (FIC). 


\section{Discussion}

Candida species are the leading etiological factor of fungal infections worldwide [43]. The number of cases caused by these pathogens is increasing, both in the general population and among hospitalized patients [44,45]. Studies conducted so far indicate that among women of reproductive age, as many as $70-75 \%$ will experience VVC at least once in their lifetime, and almost half of them (40-50\%) may experience recurrence [12,46]. To date, the most commonly isolated pathogen in women with VVC is C. albicans, detected in up to $90 \%$ of cases [10]. The nature of systemic candidiasis is often endogenous, and Candida spp. are the fourth most common trigger of infection among the patients of intensive care units. Therefore, these fungi have to be considered as a serious cause of morbidity and mortality $[19,20,47,48]$. C. albicans is responsible for more than half of all candidemias that occurs in hospitalized patients, including intensive care units and hematology departments, and $55 \%$ of all fungal infections [49,50]. Interestingly, the species belonging to the NCAC group, which are often resistant to traditional antifungal treatment, play an increasingly important role in the etiology of both VVC and BSI [10,51,52]. Numerous sources suggest that the mechanism of this resistance is multifactorial and can include incomplete penetration of antibiotics and host immune cells through the components of the extracellular matrix, initiation of structural and functional changes in biofilm cells and its environment, the ability to react to the differences in the density of the cell population by the regulation of gene expression (quorum sensing), and the expression of transport proteins that remove xenobiotics to the extracellular space (efflux pumps) $[10,12,53]$. Azoles are a common fungistatic drugs used in the treatment of fungal infections [54]. One of the most commonly prescribed medicaments from this group is fluconazole, often considered as the first-line drug in the prevention and treatment of yeast infections [55]. The wide range of indications and the extensive use of azoles have significantly contributed to the selection of resistant strains [54]. As a matter of fact, numerous resistance mechanisms responsible for this condition, as well as biofilm formation, are indicated [56]. Nevertheless, Candida spp. causing VVC clinically refractory to first-line therapy often show sensitivity to fluconazole under laboratory conditions $[57,58]$. It has been suggested that the key factor of the virulence responsible for the lack of therapeutic effects may be the ability to create biofilms $[46,51,59]$. For this reason, it is necessary to search for alternative methods of treating fungal infections based on antimicotics that effectively eradicate this structure. Antimicrobial peptides (AMPs), including Omiganan, might meet this criterion, as promising activity has already been described [38]. In the case of VVC, the MIC results obtained in this study show that fluconazole is highly active against planktonic forms of Candida. In $85 \%$ of cases of VVC isolates, the MIC values for fluconazole were $\leq 0.125 \mu \mathrm{g} / \mathrm{mL}$, which is consistent with the available data from the literature [60,61]. Apart from three strains, all BSI Candida isolates also proved to be sensitive to fluconazole-the MIC values did not exceed $16 \mu \mathrm{g} / \mathrm{mL}$. Omiganan also turned out to be active against the planktonic forms of the tested fungi from both VVC and BSI. The most common MIC values of the tested AMP were $128 \mu \mathrm{g} / \mathrm{mL}$ for VVC isolates and $256 \mu \mathrm{g} / \mathrm{mL}$ for BSI isolates. Unfortunately, taking into account previous studies on the cytotoxicity of Omiganan conducted by Jaśkiewicz et al., attention should be paid to the poor selectivity of this compound toward Candida, since the calculated selectivity index appeared to be very low (0.48) [42]. However, to assess the safety profile reliably, comprehensive research on its cytotoxicity-for example, toward the vaginal epithelium cell lines-should be conducted. Based on the obtained very high biofilm eradication concentrations of fluconazole, it should be concluded that this mycostatic compound is ineffective against fungal biofilm, which has already been emphasized in the literature $[62,63]$. On the contrary, the obtained MBECs of Omiganan were also relatively high for the majority of strains $(256 \mu \mathrm{g} / \mathrm{mL})(61 / 62)$. However, the activity of this compound against planktonic forms (MIC) was identical or similar to the activity against Candida biofilms (MBEC). In the case of $44 \%(28 / 64)$ of the strains, the MIC value was identical to the MBEC. For another 47\% (30/64), these values differed only by one order of magnitude. Considering the need to conduct more detailed studies on 
the toxicity of Omiganan, its greatest advantage may be the comparable activity against Candida in both the planktonic forms and biofilms.

The FIC indexes representing the simultaneous use of both tested drugs turned out to be particularly interesting. Although, initially, in our previous report for three strains of Candida spp., the FIC determination indicated an antagonism between Omiganan and fluconazole. However, in the course of our studies on a larger group of strains, we found an additive and/or synergistic effect [38]. In both the vaginal and blood-derived strains, addition was the most common effect, affecting the majority of $C$. albicans isolates (6/8 with VVC and 5/6 with BSI) and 100\% of the strains from the NCAC group. Among the strains that showed synergy and/or addition in the action of Omiganan and fluconazole, the MIC values for each of these substances used alone were at least two times higher than those obtained in combination. The observed outcomes demonstrate the potential of combined therapy with the use of AMPs and classic fungistatics. The likely reason for the greater effectiveness of the combination of both compounds is the complementarity of their mechanisms of action. After penetrating into the fungal cell, fluconazole inhibits the Erg11 enzyme involved in the synthesis of ergosterol, being a component of the fungal cell membrane. It has been observed that under the influence of azoles, there is a change in the fungal cell membrane correlated with the disturbance of its structure and increased permeability to ATP and $\mathrm{K}^{+}$ions, which is directly responsible for the fungistatic effect of this group of compounds $[2,64,65]$. Omiganan, on the contrary, acts directly on the fungal cell membranes, leading to their permeabilization and, as a result, cell death [38]. It is assumed that Omiganan facilitates the penetration of fluconazole into the cell interior, and thus helps to achieve its molecular target $[33,66]$. Similar observations indicating a positive effect of the combined action of fluconazole and AMPs have been observed in many other studies [38,67-70]. For example, AMPs showed synergistic activity against C. albicans not only when used with fluconazole, but also with capsofungin-a semisynthetic lipopeptide [70]. Almost identical results concerning the combination therapy of Omiganan and fluconazole were obtained with the use of retro-Omiganan [38]. In the case of fungal strains resistant to standard treatment, it seems reasonable to search for alternative forms of therapy by examining the effect of combination therapy. Such an approach may not only allow for more effective treatment of severe or recurrent fungal infections, but it will also presumably lead to a reduction of the dose of the used antifungal drug, hence lowering the risk of complications of pharmacotherapy.

\section{Conclusions}

Our present study on BSI isolates confirmed previous reports on the effectiveness of Omiganan as a biocide against Candida spp. clinical strains, particularly in biofilm forms, isolated from the vaginas of women with vulvovaginal candidiasis. Despite the observed strong antifungal properties of Omiganan, its advantage over fluconazole in inhibiting the growth of the planktonic forms of Candida was not demonstrated, but regarding the biofilms, it was still more effective than conventionally used azole. The combined use of both compounds generally showed an additive effect, but at some concentrations, they acted synergistically. The described outcome occurred at concentrations well below the MIC values for fluconazole or Omiganan when they are tested separately. Such a result indicates the possibility of reducing their concentrations in combination therapy, thus lowering the risk of side effects using combination therapy. Nevertheless, due to the limited number of tested strains and the incomplete data on the toxicity of synthetic antimicrobial peptides, especially in combination with other drugs, it is necessary to conduct further research in this area. 
Supplementary Materials: The following are available online at https: / www.mdpi.com/article/ 10.3390/antibiotics10081001/s1. Table S1. The checkerboard method. The blue color indicates fluconazole concentrations, while the green color indicates Omiganan concentrations; both cases within the range of $0.5-64 \mu \mathrm{g} / \mathrm{mL} . \mathrm{K}+$ is the positive control (microorganism growth control), and $\mathrm{K}$ - is the medium sterility control (negative control). Table S2. MIC and MBEC values $(\mu \mathrm{g} / \mathrm{mL})$ of fluconazole and Omiganan against reference Candida strains. Table S3. Distribution of MIC and MBEC values $(\mu \mathrm{g} / \mathrm{mL})$ of fluconazole and Omiganan among vaginal (VVC) Candida strains. Table S4. Distribution of MIC and MBEC values $(\mu \mathrm{g} / \mathrm{mL}$ ) of fluconazole and Omiganan among vaginal (VVC) and blood-derived (BSI) Candida strains. Table S5. Correlation between the lowest obtained FIC values and the corresponding concentration $(\mu \mathrm{g} / \mathrm{mL})$ of Omiganan, compared to the MIC $(\mu \mathrm{g} / \mathrm{mL})$ of Omiganan against 24 random selected Candida isolates.

Author Contributions: Conceptualization, J.N. and P.C.; methodology, P.C.; formal analysis, D.Ż., A.W. and P.C.; writing-original draft preparation, D.Ż. and A.W.; writing-review and editing, P.C., J.N., M.J. and D.N.; supervision, J.N. and W.K. All authors have read and agreed to the published version of the manuscript.

Funding: This research was financially supported by the Ministry of Health subvention according to number SUB.A130.19.021 from the IT Simple System of Wroclaw Medical University and by financial resources of the Students Scientific Society of Microbiologists of Wroclaw Medical University.

Institutional Review Board Statement: The article does not contain any studies of patients by any of the authors. This article does not contain studies with human or animal subjects performed by any of the authors that should have been approved by an ethics committee.

Informed Consent Statement: The article does not contain any studies in patients by any of the authors. This article does not contain studies with human or animal subjects performed by any of the authors that should have been approved by Ethics Committee.

Data Availability Statement: All data generated or analyzed during this study are included in this published article and supplementary files.

Conflicts of Interest: The authors declare no conflict of interest.

\section{References}

1. Naglik, J.R.; Challacombe, S.J.; Hube, B. Candida albicans Secreted Aspartyl Proteinases in Virulence and Pathogenesis. Microbiol. Mol. Biol. Rev. 2003, 67, 400-428. [CrossRef]

2. Staniszewska, M.; Bondaryk, M.; Piłat, J.; Siennicka, K.; Magda, U.; Kurzatkowski, W. Virulence factors of Candida albicans. Przegl Epidemiol. 2012, 66, 629-633.

3. Sidrim, J.; Júlio, C.; Rocha, M.F.G. Micologia Médica à Luz de Autores Conteponrâneos; Guanabara Koogan: Rio de Janeiro, Brazil, 2012.

4. Achkar, J.M.; Fries, B.C. Candida infections of the genitourinary tract. Clin. Microbiol. Rev. 2010, 23, 253-273. [CrossRef]

5. Anderson, M.R.; Klink, K.; Cohrssen, A. Evaluation of Vaginal Complaints. J. Am. Med. Assoc. 2004, 291, 1368-1379. [CrossRef]

6. Sobel, J.D. Vulvovaginal candidosis. Lancet 2007, 369, 1961-1971. [CrossRef]

7. Denning, D.W.; Kneale, M.; Sobel, J.D.; Rautemaa-Richardson, R. Global burden of recurrent vulvovaginal candidiasis: A systematic review. Lancet Infect. Dis. 2018, 18, e339-e347. [CrossRef]

8. Sobel, J.D.; Sobel, R. Current treatment options for vulvovaginal candidiasis caused by azole-resistant Candida species. Expert Opin Pharmacother. 2018, 19, 971-977. [CrossRef]

9. Patel, D.A.; Gillespie, B.; Sobel, J.D.; Leaman, D.; Nyirjesy, P.; Weitz, M.V.; Foxman, B. Risk factors for recurrent vulvovaginal candidiasis in women receiving maintenance antifungal therapy: Results of a prospective cohort study. Am. J. Obstet. Gynecol. 2004, 190, 644-653. [CrossRef] [PubMed]

10. Gonçalves, B.; Ferreira, C.; Alves, C.T.; Henriques, M.; Azeredo, J.; Silva, S. Vulvovaginal candidiasis: Epidemiology, microbiology and risk factors. Crit. Rev. Microbiol. 2016, 42, 905-927. [CrossRef] [PubMed]

11. Amouri, I.; Sellami, H.; Borji, N.; Abbes, S.; Sellami, A.; Cheikhrouhou, F.; Maazoun, L.; Khaled, S.; Khrouf, S.; Boujelben, Y.; et al. Epidemiological survey of vulvovaginal candidosis in Sfax, Tunisia. Mycoses 2011, 54, e499-e505. [CrossRef]

12. Brandolt, T.M.; Klafke, G.B.; Gonçalves, C.V.; Bitencourt, L.R.; de Martinez, A.M.B.; Mendes, J.F.; Meireles, M.C.A.; Xavier, M.O. Prevalence of Candida spp. in cervical-vaginal samples and the in vitro susceptibility of isolates. Braz. J. Microbiol. 2017, 48, 145-150. [CrossRef] [PubMed]

13. Nakamura-Vasconcelos, S.S.; Fiorini, A.; Zanni, P.D.; de Souza Bonfim-Mendonça, P.; Godoy, J.R.; Almeida-Apolonio, A.A.; Consolaro, M.E.L.; Svidzinski, T.I.E. Emergence of Candida glabrata in vulvovaginal candidiasis should be attributed to selective pressure or virulence ability? Arch. Gynecol. Obstet. 2017, 296, 519-526. [CrossRef] [PubMed] 
14. Sobel, J.D.; Kapernick, P.S.; Zervos, M.; Reed, B.D.; Hooton, T.; Soper, D.; Nyirjesy, P.; Heine, M.W.; Willems, J.; Panzer, H.; et al. Treatment of complicated Candida vaginitis: Comparison of single and sequential doses of fluconazole. Am. J. Obstet. Gynecol. 2001, 185, 363-369. [CrossRef]

15. Zhang, J.Y.; Liu, J.H.; Liu, F.D.; Xia, Y.H.; Wang, J.; Liu, X.; Zhang, Z.Q.; Zhu, N.; Ying, Y.; Huang, X.T. Vulvovaginal candidiasis: Species distribution, fluconazole resistance and drug efflux pump gene overexpression. Mycoses 2014, 57, 584-591. [CrossRef] [PubMed]

16. Lee, Y.; Puumala, E.; Robbins, N.; Cowen, L.E. Antifungal Drug Resistance: Molecular Mechanisms in Candida albicans and beyond. Chem. Rev. 2021, 121, 3390-3411. [CrossRef]

17. Bhattacharya, S.; Sobel, J.D.; White, T.C. A combination fluorescence assay demonstrates increased efflux pump activity as a resistance mechanism in azole-resistant vaginal Candida albicans isolates. Antimicrob. Agents Chemother. 2016, 60, 5858-5866. [CrossRef]

18. Bhattacharya, S.; Sae-Tia, S.; Fries, B.C. Candidiasis and mechanisms of antifungal resistance. Antibiotics 2020, 9, 312. [CrossRef]

19. Brandt, M.E. Candida and Candidiasis. Emerg. Infect. Dis. 2002, 8, 876. [CrossRef]

20. Enoch, D.A.; Ludlam, H.A.; Brown, N.M. Invasive fungal infections: A review of epidemiology and management options. J. Med. Microbiol. 2006, 55, 809-818. [CrossRef]

21. Schelenz, S. Management of candidiasis in the intensive care unit. J. Antimicrob. Chemother. 2008, 61, 31-34. [CrossRef]

22. O'Brien, S.N.; Blijlevens, N.M.A.; Mahfouz, T.H.; Anaissie, E.J. Infections in patients with hematological cancer: Recent developments. Hematol. Am. Soc. Hematol. Educ. Program. 2003, 438-472. [CrossRef]

23. Dabrowska, M.; Sienkiewicz, M.; Kwiatkowski, P.; Dąbrowski, M. Diagnosis and treatment of invasive Candida infections-A review article. Ann. Univ. Mariae Curie Sklodowska Sect. C Biol. 2019, 73, 47. [CrossRef]

24. Garczewska, B.; Kamińska, W.; Dzierzanowska, D. Phenotype and genotype characterization of Candida albicans strains isolated from patients hospitalized at the Children's Memorial Health Institute. Med. Dosw. Mikrobiol. 2008, 60, 231-241.

25. Barbara Modrzewska, P.K.D. Invasion of host cells by fungi progresses in several phases. Polish Parasitol. Soc. 2013, 59, 57-66.

26. Tsui, C.; Kong, E.F.; Jabra-Rizk, M.A. Pathogenesis of Candida albicans biofilm. Pathog. Dis. 2016, 74, ftw018. [CrossRef] [PubMed]

27. Garipov, M.R.; Sabirova, A.E.; Pavelyev, R.S.; Shtyrlin, N.V.; Lisovskaya, S.A.; Bondar, O.V.; Laikov, A.V.; Romanova, J.G.; Bogachev, M.I.; Kayumov, A.R.; et al. Targeting pathogenic fungi, bacteria and fungal-bacterial biofilms by newly synthesized quaternary ammonium derivative of pyridoxine and terbinafine with dual action profile. Bioorg. Chem. 2020, 104. [CrossRef]

28. Sharafutdinov, I.S.; Ozhegov, G.D.; Sabirova, A.E.; Novikova, V.V.; Lisovskaya, S.A.; Khabibrakhmanova, A.M.; Kurbangalieva, A.R.; Bogachev, M.I.; Kayumov, A.R. Increasing Susceptibility of Drug-Resistant Candida albicans to Fluconazole and Terbinafine by 2(5H)-Furanone Derivative. Molecules 2020, 25, 642. [CrossRef]

29. Peschel, A.; Vincent Collins, L. Staphylococcal resistance to antimicrobial peptides of mammalian and bacterial origin. Peptides 2001, 22, 1651-1659. [CrossRef]

30. Zasloff, M. Reconstructing one of nature's designs. Trends Pharmacol. Sci. 2000, 21, 236-238. [CrossRef]

31. Sader, H.S.; Fedler, K.A.; Rennie, R.P.; Stevens, S.; Jones, R.N. Omiganan pentahydrochloride (MBI 226), a topical 12-amino-acid cationic peptide: Spectrum of antimicrobial activity and measurements of bactericidal activity. Antimicrob. Agents Chemother. 2004, 48, 3112-3118. [CrossRef]

32. Koo, H.B.; Seo, J. Antimicrobial peptides under clinical investigation. Pept. Sci. 2019, 111, e24122. [CrossRef]

33. Melo, M.N.; Dugourd, D.; Castanho, M.A.R.B. Omiganan Pentahydrochloride in the Front Line of Clinical Applications of Antimicrobial Peptides. Recent Pat. Antiinfect. Drug Discov. 2006, 1, 201-207. [CrossRef]

34. Neubauer, D.; Jaśkiewicz, M.; Migoń, D.; Bauer, M.; Sikora, K.; Sikorska, E.; Kamysz, E.; Kamysz, W. Retro analog concept: Comparative study on physico-chemical and biological properties of selected antimicrobial peptides. Amino Acids 2017, 49, 1755-1771. [CrossRef]

35. Rijsbergen, M.; Rijneveld, R.; Todd, M.; Feiss, G.L.; Kouwenhoven, S.T.P.; Quint, K.D.; Alewijk, D.C.J.G.; Koning, M.N.C.; Klaassen, E.S.; Burggraaf, J.; et al. Results of phase 2 trials exploring the safety and efficacy of omiganan in patients with human papillomavirus-induced genital lesions. Br. J. Clin. Pharmacol. 2019. [CrossRef]

36. Ng, S.M.S.; Yap, Y.Y.A.; Cheong, J.W.D.; Ng, F.M.; Lau, Q.Y.; Barkham, T.; Teo, J.W.P.; Hill, J.; Chia, C.S.B. Antifungal peptides: A potential new class of antifungals for treating vulvovaginal candidiasis caused by fluconazole-resistant Candida albicans. J. Pept. Sci. 2017, 23, 215-221. [CrossRef]

37. Rubinchik, E.; Dugourd, D.; Algara, T.; Pasetka, C.; Friedland, H.D. Antimicrobial and antifungal activities of a novel cationic antimicrobial peptide, omiganan, in experimental skin colonisation models. Int. J. Antimicrob. Agents 2009, 34, 457-461. [CrossRef] [PubMed]

38. Czechowicz, P.; Jaśkiewicz, M.; Neubauer, D.; Gościniak, G.; Kamysz, W. Anticandidal Activity of Omiganan and Its Retro Analog Alone and in Combination with Fluconazole. Probiotics Antimicrob. Proteins 2021, 13, 1173-1182. [CrossRef] [PubMed]

39. Clinical and Laboratory Standards Institute (CLSI). Reference Method for Broth Dilution Antifungal Susceptibility Testing of Yeasts; Approved Standards-Second Edition, in CLSI Document M27-2A 2002; CLSI: Wayne, PA, USA, 2002; Volume 22, ISBN 1562384694.

40. Krom, B.P.; Cohen, J.B.; McElhaney-Feser, G.; Busscher, H.J.; Van Der Mei, H.C.; Cihlar, R.L. Conditions for optimal Candida biofilm development in microtiter plates. Methods Mol. Biol. 2009, 499, 55-62. [CrossRef]

41. Nilius, A.M. Antimicrobial Pharmacodynamics in Theory and Clinical Practice; Informa Healthcare USA: New York, NY, USA, 2002. 
42. Jaśkiewicz, M.; Neubauer, D.; Kazor, K.; Bartoszewska, S.; Kamysz, W. Antimicrobial activity of selected antimicrobial peptides against planktonic culture and biofilm of Acinetobacter baumannii. Probiotics Antimicrob. Proteins 2019, 11, 317-324. [CrossRef] [PubMed]

43. Richards, M.J.; Edwards, J.R.; Culver, D.H.; Gaynes, R.P. Nosocomial Infections in Combined Medical-Surgical Intensive Care Units in the United States. Infect. Control. Hosp. Epidemiol. 2000, 21, 510-515. [CrossRef]

44. Fridkin, S.K.; Jarvis, W.R. Epidemiology of nosocomial fungal infections. Clin. Microbiol. Rev. 1996, 9, 499-511. [CrossRef]

45. Silva, S.; Negri, M.; Henriques, M.; Oliveira, R.; Williams, D.W.; Azeredo, J. Candida glabrata, Candida parapsilosis and Candida tropicalis: Biology, epidemiology, pathogenicity and antifungal resistance. FEMS Microbiol. Rev. 2012, 36, $288-305$. [CrossRef]

46. Rodríguez-Cerdeira, C.; Gregorio, M.C.; Molares-Vila, A.; López-Barcenas, A.; Fabbrocini, G.; Bardhi, B.; Sinani, A.; Sánchez-Blanco, E.; Arenas-Guzmán, R.; Hernandez-Castro, R. Biofilms and vulvovaginal candidiasis. Colloids Surf. B Biointerfaces 2019, 174, 110-125. [CrossRef]

47. Chow, J.K.; Golan, Y.; Ruthazer, R.; Karchmer, A.W.; Carmeli, Y.; Lichtenberg, D.; Chawla, V.; Young, J.; Hadley, S. Factors associated with candidemia caused by non-albicans Candida species versus Candida albicans in the intensive care unit. Clin. Infect. Dis. 2008, 46, 1206-1213. [CrossRef]

48. Ostrosky-Zeichner, L.; Pappas, P.G. Invasive candidiasis in the intensive care unit. Crit. Care Med. 2006, 34, 857-863. [CrossRef]

49. Parmeland, L.; Gazon, M.; Guerin, C.; Argaud, L.; Lehot, J.J.; Bastien, O.; Allaouchiche, B.; Michallet, M.; Picot, S.; Bienvenu, A.L.; et al. Candida albicans and non-Candida albicans fungemia in an institutional hospital during a decade. Med. Mycol. 2013, 51, 33-37. [CrossRef]

50. Pappas, P.G.; Lionakis, M.S.; Arendrup, M.C.; Ostrosky-Zeichner, L.; Kullberg, B.J. Invasive candidiasis. Nat. Rev. Dis. Prim. 2018, 4, 18026. [CrossRef] [PubMed]

51. Silva, S.; Henriques, M.; Martins, A.; Oliveira, R.; Williams, D.; Azeredo, J. Biofilms of non-Candida albicans Candida species: Quantification, structure and matrix composition. Med. Mycol. 2009, 47, 681-689. [CrossRef] [PubMed]

52. Chander, J.; Singla, N.; Sidhu, S.K.; Gombar, S. Epidemiology of Candida blood stream infections: Experience of a tertiary care centre in North India. J. Infect. Dev. Ctries. 2013, 7, 670-675. [CrossRef] [PubMed]

53. Peters, B.M.; Yano, J.; Noverr, M.C.; Fidel, P.L. Candida Vaginitis: When Opportunism Knocks, the Host Responds. PLoS Pathog. 2014, 10, e1003965. [CrossRef]

54. Robbins, N.; Uppuluri, P.; Nett, J.; Rajendran, R.; Ramage, G.; Lopez-Ribot, J.L.; Andes, D.; Cowen, L.E. Hsp90 Governs Dispersion and Drug Resistance of Fungal Biofilms. PLoS Pathog. 2011, 7, e1002257. [CrossRef]

55. Ciszewski, M.; Czekaj, T. Grzybicze zakażenia szpitalne-narastające zagrożenie. Nowa Med. 2014, 2, 73-76.

56. Bondaryk, M.; Kurzaątkowski, W.; Staniszewska, M. Antifungal agents commonly used in the superficial and mucosal candidiasis treatment: Mode of action and resistance development. Postep. Dermatol. Alergol. 2013, 30, 293-301. [CrossRef] [PubMed]

57. Reboli, A.C.; Rotstein, C.; Pappas, P.G.; Chapman, S.W.; Kett, D.H.; Kumar, D.; Betts, R.; Wible, M.; Goldstein, B.P.; Schranz, J.; et al. Anidulafungin versus Fluconazole for Invasive Candidiasis. N. Engl. J. Med. 2007, 356, 2472-2482. [CrossRef] [PubMed]

58. Maiolo, E.M.; Tafin, U.F.; Borens, O.; Trampuz, A. Activities of fluconazole, caspofungin, anidulafungin, and amphotericin b on planktonic and biofilm Candida species determined by microcalorimetry. Antimicrob. Agents Chemother. 2014, 58, $2709-2717$. [CrossRef]

59. Czechowicz, P.; Nowicka, J. Antimicrobial activity of lipopeptides. Postep. Mikrobiol. 2018, 57, 213-226. [CrossRef]

60. Tellapragada, C.; Eshwara, V.K.; Johar, R.; Shaw, T.; Malik, N.; Bhat, P.V.; Kamath, A.; Mukhopadhyay, C. Antifungal Susceptibility Patterns, In Vitro Production of Virulence Factors, and Evaluation of Diagnostic Modalities for the Speciation of Pathogenic Candida from Blood Stream Infections and Vulvovaginal Candidiasis. J. Pathog. 2014, 2014, 1-8. [CrossRef] [PubMed]

61. Pahwa, N.; Kumar, R. Species distribution and drug susceptibility of Candida in clinical isolates from a tertiary care centre at Indore. Indian J. Med. Microbiol. 2014, 32, 44-48. [CrossRef]

62. Tomaszewski, J. The statement of polish gynecological society experts on the etiology and treatment of recurrent vulvovaginal candidiasis. Ginekol. Pol. 2011, 82, 869-873.

63. Sherry, L.; Kean, R.; McKloud, E.; O’Donnell, L.E.; Metcalfe, R.; Jones, B.L.; Ramage, G. Biofilms formed by isolates from recurrent vulvovaginal candidiasis patients are heterogeneous and insensitive to fluconazole. Antimicrob. Agents Chemother. 2017, 61, e01065-17. [CrossRef] [PubMed]

64. Venisse, N.; Grégoire, N.; Marliat, M.; Couet, W. Mechanism-based pharmacokinetic-pharmacodynamic models of in vitro fungistatic and fungicidal effects against Candida albicans. Antimicrob. Agents Chemother. 2008, 52, 937-943. [CrossRef] [PubMed]

65. Mertas, A. Aktywność przeciwgrzybicza flukonazolu wobec klinicznych szczepów Candida albicans oraz innych Candida spp.-一Przegląd badań in vitro przeprowadzonych w różnych ośrodkach medycznych the antifungal activity of fl uconazole against clinical of the researc. Ann. Acad. Med. Silesiensis 2011, 65, 29-37.

66. Singh, K.; Rani, J. Sequential and Structural Aspects of Antifungal Peptides from Animals, Bacteria and Fungi Based on Bioinformatics Tools. Probiotics Antimicrob. Proteins 2016, 8, 85-101. [CrossRef]

67. De Aguiar, F.L.L.; Cavalcante, C.; dos Santos Fontenelle, R.O.; Falcão, C.B.; Andreu, D.; Rádis-Baptista, G. The antiproliferative peptide C $\operatorname{tn}[15-34]$ is active against multidrug-resistant yeasts Candida albicans and Cryptococcus neoformans. J. Appl. Microbiol. 2020, 128, 414-425. [CrossRef] [PubMed] 
68. Dawgul, M.; Barańska-Rybak, W.; Bielińska, S.; Nowicki, R.; Kamysz, W. Wpływ peptydów przeciwdrobnoustrojowych na biofilm Candida The influence of antimicrobial peptides on Candida biofilm. Alerg. Astma Immunol. 2010, 15, $220-225$.

69. Sun, W.; Zhang, L.; Lu, X.; Feng, L.; Sun, S. The synergistic antifungal effects of sodium phenylbutyrate combined with azoles against Candida albicans via the regulation of the ras-cAMP-PKA signalling pathway and virulence. Can. J. Microbiol. 2019, 65, 105-115. [CrossRef] [PubMed]

70. Maurya, I.K.; Thota, C.K.; Sharma, J.; Tupe, S.G.; Chaudhary, P.; Singh, M.K.; Thakur, I.S.; Deshpande, M.; Prasad, R.; Chauhan, V.S. Mechanism of action of novel synthetic dodecapeptides against Candida albicans. Biochim. Biophys. Acta Gen. Subj. 2013, 1830, 5193-5203. [CrossRef] 